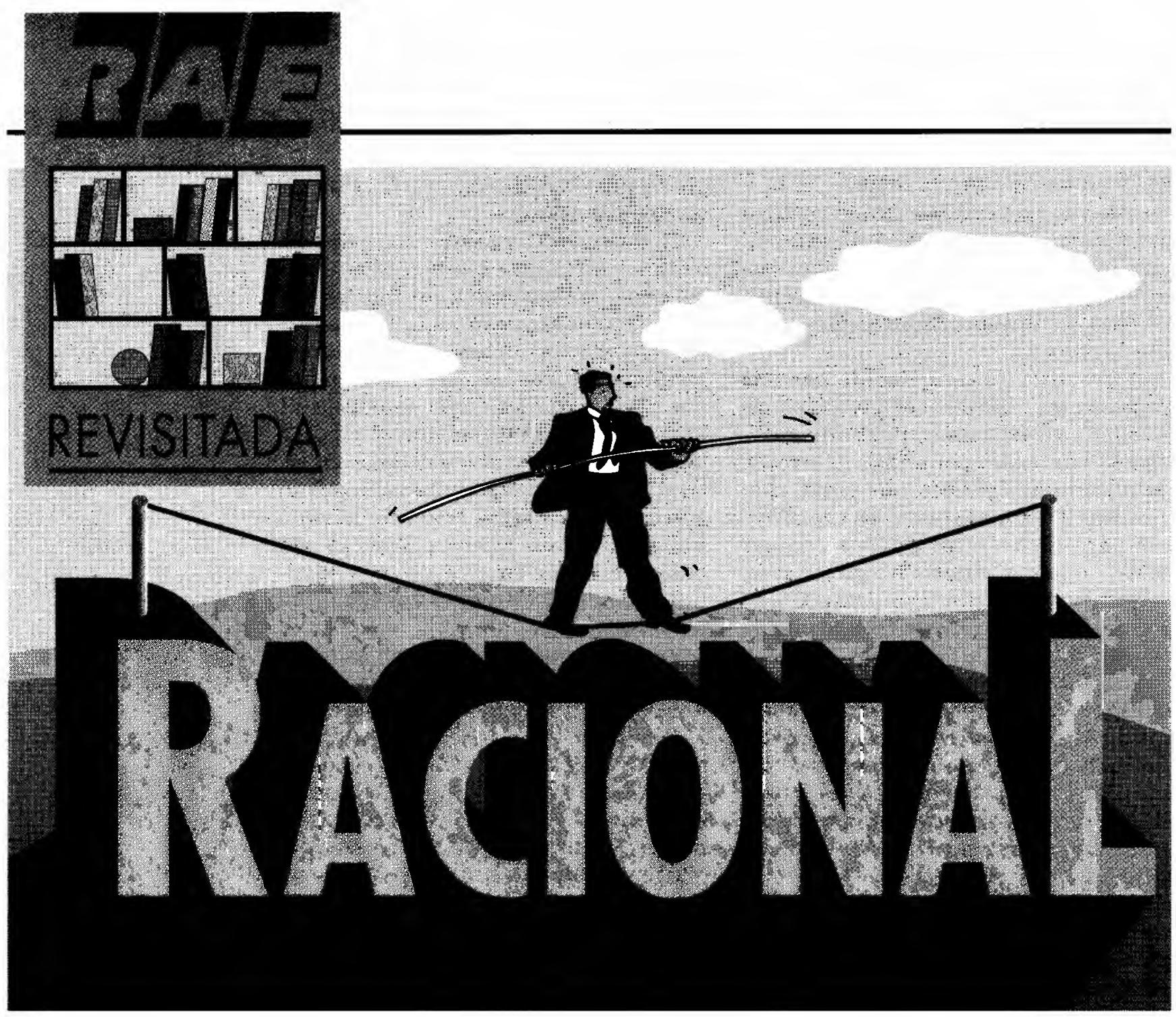

\title{
SOBRE O EMPREGO DO TERMO RACIONAL EM ECONOMIA E ADMINISTRAÇÃO
}

\section{- José Carlos Pereira}

Ex-professor do Departamento de Ciências Sociais da antiga Faculdade de Filosofia, Ciências e Letras da USP. Atualmente Professor Associado Aposentado do Departamento de Medicina Social da Faculdade de Medicina de Ribeirão Preto da USP.

* RESUMO: Este artigo foi redigido em 76 e publicado no começo de 77. Nele é discutido o significado do termo racional. $A$ análise é exemplificada através do que se considera uma ação empresarial racional. A adequação dos meios utilizados aos fins propostos constitui o caráter fundamental do termo. Os meios, porém, devem ser os socialmente aceitos. Além do mais, a ação racional compreende a previsão das suas conseqüências sobre a consecução de outros objetivos, gerais e específicos.
* PALAVRAS-CHAVE: Racionalidade, ação racional, comportamento empresarial, previsão das conseqüencias, eficiência administrativa, meios e fins, valores sociais, ação social.

* ABSTRACT: This paper was written in $76^{\prime}$ and published in the beginning of 77. In this is discussed the meaning of the term rational. The analysis is made through the use of an example of what is considered a rational entrepreneurial action. The adequacy of the used ways for the proposed objectives is the fundamental character of the term. The ways, however, should be accepted on social grounds. And more, the rational action comprises the prevision of this consequences on the achievement of other specific and general objectives.

* KEY WORDS: Rationality, rational action, entrepreneurial behavior, prevision of consequences, administrative efficiency, ways and aims, social values, social action.

São Paulo, 33(3):76-83 Mai./Jun. 1993 


\section{INTRODUÇĀO}

É corrente, hoje, encontrarmos como principal justificativa de medidas de caráter social em geral, mas especialmente em matéria econômica e administrativa, o fato de elas serem "racionais". Os tecnocratas sobretudo, assim como os simples técnicos ${ }^{1}$, usam e abusam do termo. Mas não apenas estes tendem a justificar as medidas propostas com o quase mágico qualificativo de "racionais". Também políticos (em grande parte influenciados por aqueles, que os assessoram) e mesmo cientistas sociais, em seus trabalhos, usam abusivamente o termo.

Na verdade, há uma razão para isso. É que inexistem princípios perfeitamente definidos que esclareçam o que seja racional. O termo (e seu oposto irracional) é extremamente ambíguo para permitir uma definição que determine os limites de sua extensão e que convenha a todo o definido e apenas ao definido. Em vista disso, deparamo-nos freqüentemente com definições parciais e mesmo inexatas, das quais, não necessariamente, os autores se dão conta. Em certos momentos, o significado que se está dando ao termo, se não é verdadeiro, também não é falso. Em outras palavras, o autor está lhe dando um significado parcial, que atende a seus propósitos.

Em outros casos, porém, uma análise mais aprofundada nos revelará incompreensão do termo, sendo inexata a sinonímia que implícita ou explicitamente se está estabelecendo. Por exemplo, tomar como sinônimo de racional conceitos como os de "moderno", "novo", "burocrático", "técnico", "científico" etc., se tais atributos não constituem condição ou fator que seja parte significativa da totalidade representada pelo conceito de racional. Discutir todas as dificuldades implicadas na definição do termo seria uma tarefa por demais ambiciosa. Tentaremos aqui, tão somente, indicar as principais dificuldades (pelo menos em nosso entender) que se antepõem ao desiderato, e indicar as contradições que surgem, em se tratando dos vários niveis do social, ao considerar esta ou aquela ação social como racional.
Uma das maiores fontes de erros está no fato de que cada sociedade, cultura, estrato, classe, grupo etc. tende a considerar certas ações sociais, e os valores a elas associados, como mais "racionais" em relação àqueles típicos de outras sociedades, culturas etc. Notável, entretanto, é como homens inteligentes e capazes vangloriam-se de agir, pensar e sentir "racionalmente" em relação ao homem comum de sua sociedade e, mais ainda,

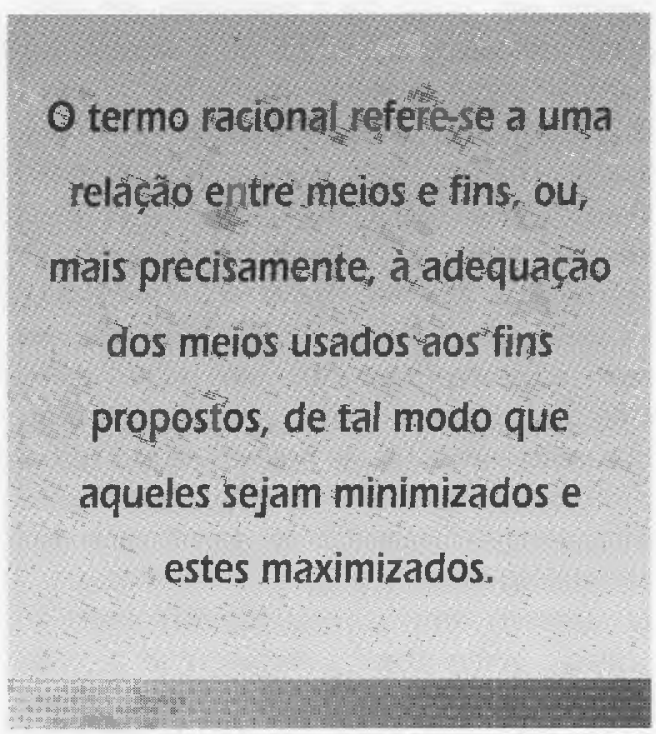

em relação ao de outras, sem perceber que, inconscientemente, estão representando interesses classistas ou outros vigentes em sua própria sociedade. É claro que há pessoas que têm uma consciência mais ou menos desenvolvida dessa situação. Mas o comum é estarem tão imbuídas da ideologia que lhes foi inculcada que se esquecem de seus "idolos", acabam não duvidando, não discernindo, desconhecendo que os valores que defendem e pelos quais se batem podem ser questionáveis, que pode haver outros modos de agir, pensar e sentir perfeitamente defensáveis, desde que se mude o enfoque.

\section{CONSIDERAÇÕES GERAIS}

Tomando o aspecto mais evidente, o termo racional refere-se a uma relação entre meios e fins, ou, mais precisamente, à adequação dos meios usados aos fins propostos. $O$ adjetivo racional só se aplica aos meios, os únicos que podem ser escalonados, técnica e cientificamente,
1. Não nos estenderemos na distinçāo entre tecnocrata e técnico. Para nossos fins limitados, apenas diremos que entendemos como tecnocratas aqueles que possuem conhecimentos técnicos adquiridos e desenvolvidos atraves da educácão científica e que os utilizam como forma de influenciar a realidade social em maior ou menor escala; denominados técnicos, por outro lado, os que possuem os ditos conhecimentos sem ter uma influência definida no curso dos acontecimentos (Conforme MEYNAUD, Jean. La tecnocracia, mito o realida de? Madrid: Tecnos, 1968, cap. 1. sección 1). Da mesma forma Carlos Estevam Martins entende como tecnocrata "o tecnológo que foi capaz de afirmar o seu próprio poder, o poder inesente à sua capacitação técnico-cientifica", enquanto o tecnológo que nẵo se auto-afirmou ou é "um simples assessor técnico" ou "um tecnoburocrata", que não possui poder especifico. comandado unicamente "por meio de instrumentos de poder puramente burocráticos" (Conforme Tecnocracia e burocracia Estudos CEBRAP 2, p. 146, out 1972). 
em relação a um padrão unívoco, quaisquer que sejam as medidas utilizadas. Dado que os fins são determinados valorativamente, é extremamente difícil chegar-se a um acordo quanto à sua racionalidade, uma vez que a um fim sempre se pode contrapor outro, baseado em outro sistema de valores.

Neste caso, o caráter de racional é confirmado pela consecução dos resultados esperados. Tal confirmação ocorre $a$ posteriori, em vista de a previsão ter sido acertada: usaram-se tais ou quais meios para se atingir determinados fins, e esses fins foram atingidos. De certo modo há, aqui, uma analogia com a definição de verdade cientifíca: uma teoria científica adquire tanto maior validade quando os resultados que ela prevê se confirmam. Dizemos analogia apenas porque ela, de fato, pode ser bastante correta nas ciências ditas exatas, mas o é em muito menor grau nas ciências humanas, em que a previsão, ao passar a fazer parte da realidade social, interfere no desenrolar dos acontecimentos. Neste nível, portanto, este aspecto tem um significado restrito àquelas ações que a previsão não modificou a realidade de modo tão marcante que pudesse, por si própria, alterar o resultado esperado. Em se tratando de ação econômica e administrativa, em que a realidade na qual se age é social, é evidente que se precisa considerar a alteração dessa mesma realidade em face da previsão feita, para que possamos atribuir o caráter de racional à conduta seguida.

Outra consideração geral que podemos fazer é que a utilização de comportamentos tradicionais, numa dada situação e dispondo-se de determinados recursos humanos, não significa necessariamente que a ação é menos racional. $O$ que dá à ação o atributo de racional é o conhecimento, tão perfeito quanto possível, dentro da situação dada, de que a utilização de tais ou quais meios permitirá alcançar, com o mínimo de esforços, os fins visados. Somente seria irracional utilizar condutas tradicionais com base em intuições, em explicações místicas, sagradas etc. Se o agente tem consciência plena de que atingirá melhor os objetivos que tem em vista mediante o uso de comportamentos tradicionais, sua ação é racional.
Nem mesmo a intuição pode, sem maior exame, ser tida sempre como fonte de irracionalidade. Como sabem todos os planejadores, ela é um importante fator de tomada de decisões. É certo que há determinados tipos de intuição com forte matiz emocional, baseados em impressões pouco especificadas que, talvez, se possam constituir na fonte mencionada. Há, contudo, uma "intuição axiomática", que é um juízo imediato, cujos passos mentais, apesar de não poderem ser expressos verbal ou matematicamente, indicam uma percepção precisa, pelo intelecto, de uma relação necessária entre determinados elementos de uma situação. Talvez essa intuição possa ser considerada racionalmente válida como base de tomada de decisões. Esta é, no entanto, uma situação extrema. De modo geral, o comportamento racional pode ser explicado, sendo fundamentado numa explicação probabilística, lógica ou, mais freqüentemente, demonstrada pela experiência. Nestes últimos sentidos pode-se dizer que a ação está sendo orientada com objetividade porque, cientificamente, sabe-se que os fins que se têm em vista podem ser realizados pelos meios de que se dispõe, fazendo-se as correções necessárias oriundas da introdução na situação de novos acontecimentos, inclusive a previsão, como dissemos.

A referência à previsão permite-nos indicar outro aspecto relevante: o comportamento racional deve levar em consideração, necessariamente, o comportamento esperado dos outros. De fato, é preciso compreender o mais perfeitamente possível esse comportamento esperado, para que não haja mal-entendidos danosos à consecução dos objetivos propostos. Assim, se não compreendemos os outros, frustramos-lhes as expectativas, e sua resposta não será favorável à nossa ação. Por outro lado, o sentido dado à nossa ação deve ser tal que, baseados no conhecimento que temos dos outros, obtenhamos deles a resposta por nós esperada. Em termos do que Max Weber entende por ação social, diremos que a ação racional deve se basear na compreensão mútua, a mais perfeita possível, dentro dos limites das condições dadas, do significado recíproco das ações, de modo que alter e ego (que tanto podem ser pessoas, como grupos, 
estratos, classes etc.) correspondam às intenções uns dos outros. Seria exigir demais, evidentemente, querer que todos os participantes da ação entendessem plenamente o signuficado das ações uns dos outros. Isto, entretanto, não é necessário. É suficiente que eles não se desviem demasiadamente desse significado.

O âmbito do termo racional implica também o máximo domínio possível das conseqüências futuras da ação. É claro que seria esperar demais (uma vez que estamos lidando com pessoas e não com um mecanismo cibernético) pretender que sejamos capazes de antecipar todas as consequiências futuras de nossas ações presentes. Entretanto, pode-se considerar que é uma característica fundamental da ação racional a capacidade de prever os possíveis acontecimentos futuros gerados pela dinâmica decorrente da conduta presente. Isto é, a ação, para ser considerada plenamente racional, vincula-se a uma perspectiva futura, a mais longínqua possível dentro das limitações inevitáveis do conhecimento da situação. Em outras palavras, quanto mais a ação presente não prejudique os objetivos futuros, mas, pelo contrário, venha a favorecê-los, tanto mais a ação deverá ser considerada racional.

Finalmente, entendemos como outro atributo básico do termo racional a criação da situação favorável à consecução dos objetivos propostos pelo sujeito da ação. É certo que os homens, como diz Marx, "fazem a História não como a querem e sim sob circunstâncias dadas, legadas e trasnsmitidas pelo passado". O fato é que eles a fazem, e uns, pelo seu prestígio, poder e riqueza, estão em condições de influir mais decisivamente no curso dos acontecimentos. Assim, se de um lado o comportamento é restringido pelo meio social, de outro, o dinamismo da situação pode ser tal que permita que os desejos e necessidades que pretendemos sejam atingidos pela manipulação da situação no sentido de que nossos objetivos sejam alcançados mais fácil e rapidamente, sem conseqüências negativas para o futuro. A reciprocidade mencionada pode ser então utilizada, dependendo especialmente do conhecimento da citada situação e de uma consciência tão perfeita quanto possível dos objetivos a serem alcançados e dos meios a serem utilizados.

\section{A RACIONALIDADE DA AÇÃO EMPRESARIAL}

As considerações gerais feitas anteriormente podem ser melhor entendidas se as aplicarmos ao âmbito da ação empresarial. Esta, como a compreendemos, envolve uma interação contínua entre a empresa e o sistema sócio-políticoeconômico com toda a sua historicidade, na qual aquela ação está inserida. Em determinados períodos, as condiçōes e fatores sociais globais supõem uma aten-

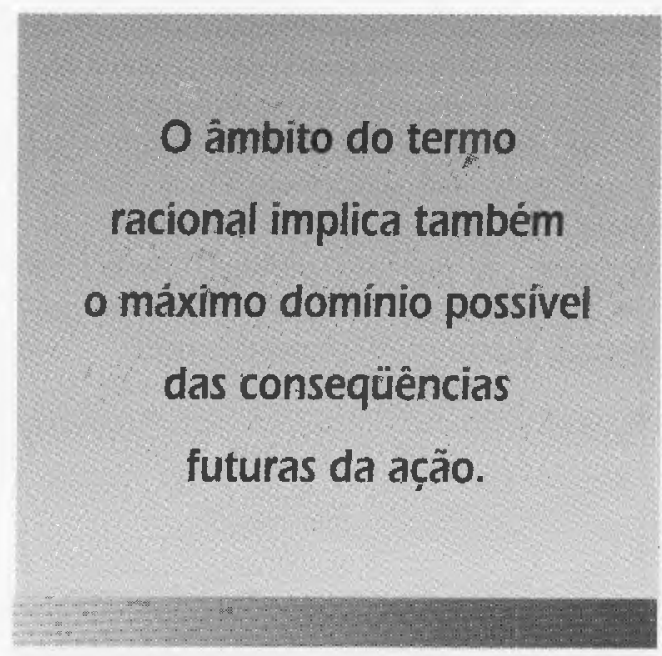

ção maior à organização interna da empresa. Em outros, em face das condições gerais, conjunturais ou estruturais externas à empresa, o alcançar racionalmente seus objetivos, que são os da administração, implica, inversamente, uma preocupação maior com essas condições gerais e não propriamente com a organização interna da empresa. $\mathrm{Ou}$, mais precisamente, a ação empresarial tem que se dedicar à manutenção de um equilíbrio, ainda que instável, entre os dois pratos da balança: a empresa e o sistema social inclusivo.

A ação empresarial racional, portanto, significa que se determine, em face do conjunto de condições e fatores gerais, as pressões a serem exercidas numa ou noutra direção. Mais: a prioridade a ser dada à organização interna ou à situação exterior à empresa vai depender do setor em que esta se encontrar. Assim sendo, pode ser que empresas de diferentes setores, apresentando graus semelhantes de racionalidade quanto à sua organização interna, obtenham resultados diferentes quan- 
2. Conforme MARX, Karl. El capital, crítica de la economía poIftica. Tradução Wescelao Roces. $2^{a}$ edição, México: Fondo de Cultura Económica, v. 3 , 1959, p. 256.

3. Considere-se, ainda, que esses valores tendem a variar de uma camada social para outra, dentro da mesma sociedade e cultura. Daí produzirem-se, especialmente nas modernas sociedades complexas e diferenciadas, freqüentes conflitos normativos. Diferindo as normas grupais das gerais, como as normas de um grupo parcial para outro, haverá sempre um grau maior ou menor de diversidade quanto ao que deva ser considerado (se analisada a questão desse ângulo) um comportamento "raciona!", no caso, "normal".

4. Conforme MERTON, Robert K. Social theory and social structure. New York: The Free Press, 1965, cap. 4: Social structure and anomie, e 5: ContInuities in the theory of social structure and anomie.

5. GODELIER, Maurice. Racionalidade e irracionalidade na economia. Trad. Rio de Janeiro: Tempo Brasileiro, p. 24.

6. Esta coerência, contudo, como jả afirmamos atrás, dificilmente pode ser atingida nas condicoōes reais de funcionamento e dinämica do sistema, já que haverá sempre divergências entre os vários fins perseguidos pelo empresariado que é a camada social que estamos tomando para exemplo. to aos seus objetivos básicos em virtude de se depararem com condições exteriores dessemelhantes. Neste sentido, muitas empresas comumente consideradas racionais, por apresentarem uma disposição mais ou menos rígida de elementos materiais e humanos, a existência de uma calculabilidade bastante precisa, a estimativa relativamente exata da situação do mercado consumidor, de mão-de-obra etc. obtêm muitas vezes resultados inferiores aos de outras, em que não está presente a mesma calculabilidade. Neste caso, a pressão exercida sobre um dos pratos da balança foi excessiva, não se ajustando às condições vigentes na sociedade e na economia. Essas empresas, pois, "idealmente racionais", desvinculam-se da situação na qual estão imersas e à qual deveriam ajustar-se. Objetivando nosso pensamento: seu mercado pode ser tão favorável que medidas tidas como racionais acabam, na verdade, não o sendo tanto.

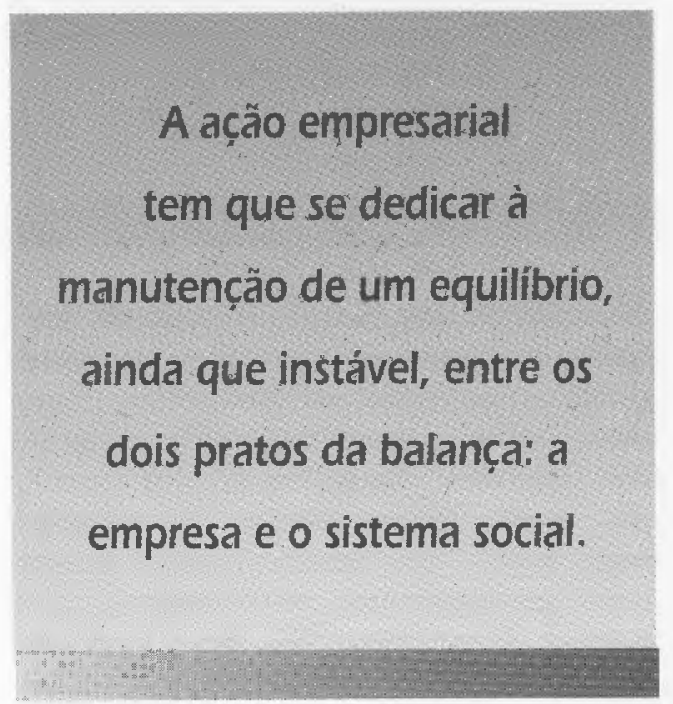

Consideramos conveniente abordar a questão do que seja racional do ângulo da empresa, ou melhor dito, do empreendimento capitalista, porque ele proporciona uma excelente oportunidade para mostrar quão difícil e escorregadio pode ser o uso de termo racional. De fato, pareceria não haver problema maior quanto ao que deveria ser considerado o comportamento racional do administrador de uma empresa capitalista, uma vez que, inquestionavelmente, "a taxa de lucro é a mola propulsora da produção capitalista, que só produz o que se pode produzir com lucro e à medida que este pode ser obtido" 2 .
Conseqüentemente, seria racional o emprego dos meios tecnicamente mais apropriados para atingir esse objetivo tão bem determinado. Com isso se evitaria a delicada questão político-ideológica da determinação dos fins, já ques estes são dados por antecipação. A análise se cingiria a um critério objetivo: a fixação dos meios técnicos mais eficentes para alcançar esse alvo bem delimitado, dentro de um sistema capitalista concreto de produção, num estágio dado de seu desenvolvimento. Em outras palavras, elidida a discussão dos fins, poderíamos evitar os juízos de valor.

Entretanto, o problema não pode ser obviado com essa facilidade. Isto porque o comportamento social se pauta sempre por outros critérios que não apenas técnicos. O meio tecnicamente mais eficaz pode não ser conforme aos valores sociais. De fato, o sistema valorativo orienta, e mesmo determina, o que vai ou não ser considerado bom, mau, condenável, admissível. ${ }^{3}$ Nessas condições, dada a significação deste sistema para a vida em sociedade, o comportamento voltado unicamente para a aquisição de bens, guiado apenas por considerações técnicas, seria "anormal", um caso-limite que dificilmente poderá encontrar comprovação empírica. Disso podemos concluir que, na realidade, os meios empregados para alcançar determinado fim, para serem racionais, devem ser os mais eficazes, mas dentre os socialmente permissíveis. Merton teve oportunidade de destacar esse aspecto, mostrando que os meios que se aceitam como legítimos estão limitados (embora em grau freqüentemente variável) pelas normas institucionalizadas. Como assinala, o uso indiscriminado de meios, independentemente de considerações como as citadas, caracteriza uma das modalidades principais do comportamento "divergente". ${ }^{4}$

Essas mesmas considerações, de certo modo, finam com a afirmação de Godelier, segundo a qual uma pesquisa sobre a racionalidade econômica, para produzir conhecimentos científicos, exige que o sistema econômico seja definido em termos reais, isto é, em termos de estrutura; que a estrutura específica do sistema "seja conhecida, ou suposta como tal, para que a racionalidade do comportamento do agente 
econômico, no seio desse sistema, seja analisável" e que também seja dada e conhecida a hierarquia dos fins-objetivos dos membros da sociedade estudada ${ }^{5}$. Buscando definir o comportamento racional de um dos agentes do sistema - o empresário patenteia-se que seu comportamento adquiriria uma racionalidade maior se :

a. seus fins fossem coerentes ${ }^{6}$;

b. usasse os meios apropriados para obter - máximo rendimento na consecução dos fins;

c. meios e fins fossem socialmente aprovados em termos de normas gerais. Fixadas estas condiçōes, entende-se que o comportamento racional, comumente considerado como aquele que, de um dado dispêndio de meios, obtém a máxima realização do fim, ou que, dado o fim, usa o mínimo de meios, é válido dentro das limitações apontadas.

Em outras palavras, a racionalidade do agente "empresário" está intimamente associada à eficiência com a qual ele realize os valores e objetivos do sistema econômico capitalista. Mas, nessa realização, é lhe imposta a necessidade de se ajustar a condiçöes dadas correspondentes à estrutura das relações de produção, ao desenvolvimento das forças produtivas, ao sistema valorativo etc. Em última análise, como assinala Godelier, a racionalidade econômica é um aspecto de uma racionalidade mais ampla, a da vida social. Em conseqüência, o problema é relativizado. A definição da racionalidade econômica nunca pode ser definitiva, mas sempre provisória, podendo o racional de hoje tornar-se o irracional de amanhã. ${ }^{7}$

Devemos notar, no entanto, que no plano da ação restrita, concernente à organização da empresa para a produção do lucro, dentro, portanto, de condições bem determinadas, o conceito de comportamento racional aplicado ao agente econômico "empresário" adquire, necessariamente, um sentido limitado, mais concreto. Cabe aqui relacionar "racional" à eficiência com que ele busca alcançar um só fim: a maximização dos lucros. $\mathrm{O}$ comportamento desse agente, encarado isoladamente, haverá de ter, sobretudo, e de fato tem, o caráter de escolha da me- lhor alternativa dentro de uma situação definida: dadas as condiçôes (econômicas, sociais, políticas, culturais, jurídicas etc.), agirá racionalmente quando conseguir uma combinação ótima dos elementos estratégicos em jogo para realizar o fim buscado. ${ }^{8}$ Tal comportamento constituirá o que podemos chamar de "racionalidade interna", isto é, aquela de que deve ser dotado o empresário em sua função de "gerente" da empresa, por assim dizer."

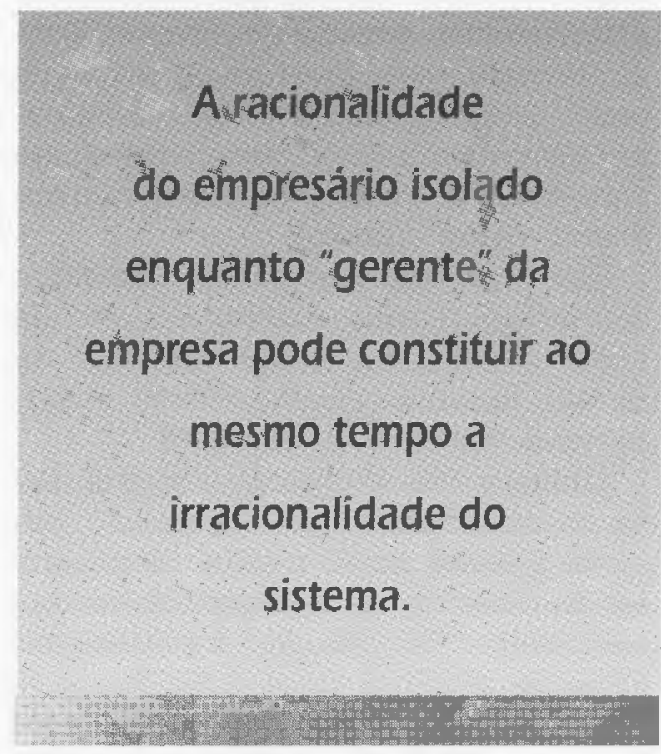

Neste plano da racionalidade interna (isto é, no da organização da empresa) fica claro, portanto, que o empresário, para agir racionalmente, deve levar em conta a situação histórico-social, as condiçōes concretas do meio em que a empresa está inserida e com o qual ela deve relacionarse. Nesse sentido, seu comportamento não será necessariamente racional se, pura e simplesmente, transplanta os modelos de organização, valores, instituiçōes e técnicas vigentes nos países mais avançados, pois as condições econômicas e sócio-culturais vigentes no Brasil, por exemplo, não contêm (e talvez nem mesmo cheguem algum dia a conter) os elementos possibilitadores dessa transplantação ${ }^{10}$. Em outras palavras, a imitação de técnicas e modelos organizacionais importados não garante, por si só, mínimos satisfatórios de eficácia, uma vez que seu rendimento "depende do agente humano e das condições em que ele atua socialmente" 11 . Por isso mesmo, sob este as-
7. Conforme GODELIER, Maurice. Op. cit. p. 131. Estas conclusóes fundamentais do autor citado podem ser melhor compreendidas se dissermos que, para ele, a hipótese da irracionalidade do comportamento dos indivíduos de sociedades primitivas ou tradicionais "não pōem em evidência senāo a ideologia dos que aceitam sem crítica os preconceitos das sociedades capitalistas ocidentais em relação a si mesmas $e$ às outras sociedades"(p. 58-9). Isto é, a humanidade não teria aguardado o capitalismo para aprender a economizar seus esforços: (...) "toda informação etnológica e histórica nos mostra que, em todas as sociedades, individuos e grupos procuram maximizar fins cujo contevido e hierarquia exprimem a dominância de certas relações sociais (...) sobre as outras e se encontram baseadas na própria estrutura de cada tipo de sociedade" (p.323).

\section{Idem, ibidem, p. 44-66}

9. De certo modo, podemos relacionar essa "racionalidade" interna ao que Karl Mannheim denomina racionalidade funcional. Usa ele o termo racionalidade (ou irracionalidade) em dois sentidos, aos quais chama de "substancial" e "funcional". Na definição da racionalidade funcional, destaca 0 aspecto fundamental do canceito, no sentido em que o estamos usando aqui, ou seja, a relação entre meios e fins. Assim é que entende por ta. termo "uma série de medidas organizadas de forma a levar a um objetivo previamente definido, recebendo todos os elementos dessa série de atos uma posição e um papel funcionais. Tal organização funcional de uma série de atos estará, por outro lado, em suas melhores condições quando, para atingir - objetivo, coordena os meios mais eficientemente"(Conforme MANNHEIM, Karl. O homem e a sociedade, estudos sobre a estrutura social moderna. Trad. Waltensir Dutra, Rio de Janeiro: Zahar, 1962, p. 63.

10. Contorme FERNANDES, Florestan. Mudanças sociais no Brasil. São Paulo: Difusão Européia do Livro, 1960, p. 58.

11. Idem, ibidem, p. 59. 
12. Idem, ibidem, p. 60.

13. "Enquanto na manufatura, a lei férrea da proporcionalidade prescreve determinadas massas de operários a determinadas funções, na distribuição dos produtores de mercadorias e de seus meios de produção entre os diversos ramos sociais de trabalho reinam, em misturas caóticas, o acaso e a arbritariedade. Claro está que as diversas esferas de producão procuram manter-se constantemente em equilíbrio (...) Esta tendência constante, porém (...) só se manifesta como reação contra $O$ desequilibrio constante. A norma, que no regime de divisão do trabalho dentro da fábrica se segue a priori, como um plano preestabelecido, na divisão do trabalho dentro da sociedade só governa a posteriori, como uma lei interna, muda, perceptível tão somente nas mudanças barométricas dos preços do mercado e como algo que se impõe ao capricho e à arbritariedade dos produtores de mercadorias (...) Na sociedade do regime capitalista de produçāo, a anarquia da divisão social do trabatho e o despotismo da divisão do trabalho na manufatura condicionam-se reciprocamente". (Conforme MARX Karl. Op. cit. v. 1, p. 289-90). Alicerçando-se neste trecho afirma Luiz Pereira, com propriedade: "se de um lado a racionalidade no interior da unidade de trabalho é imposta pela irracionalidade do sistema global de produção de bens e serviços, por outro essa racionalidade 'interna' (...) em função do lucro condiciona e determina a irracionalidade 'externa' do sistema de unidades de trabatho" (Conforme PEREIRA, Luiz. Trabalho e desenvolvimento no Brasil.São Paulo: Difusāo Européia do livro, 1965, p. 35-6). pecto restrito "a racionalização da empresa industrial não pode ser levada além dos limites em que os modelos racionais de pensamento $e$ de ação são exploráveis com eficácia no comportamento cotidiano". ${ }^{12}$

Essa racionalidade interna, porém (e isto é fundamental), freqüentemente se choca com os interesses gerais do sistema global do qual a empresa é parte. $\mathrm{Na}$ verdade, um comportamento eminentemente racional por parte do empresário isolado, comportamento considerado o objetivo básico da empresa capitalista, pode debilitar esse mesmo sistema. Estaríamos em face do que Merton chama de uma "função latente", no caso, a conseqüência objetiva não-conscientemente perseguida e desejada do comportamento empresarial racional.

Marx, especialmente, já salientara a contradição entre a "racionalidade" da divisão técnica e a "irracionalidade" da divisão social do trabalho, e como ambas se condicionam reciprocamente. ${ }^{13}$

Também Max Weber, ao distinguir entre racionalidade formal e material ${ }^{14}, \mathrm{ob}-$ serva que elas quase sempre discrepam, sendo raros os casos empíricos em que coincidem. "Pois (diz ele), a racionalidade formal de cálculo em dinheiro não diz, em si, nada sobre a natureza da distribuição dos bens naturais". Embora afirme que nos últimos decênios (escrevia na segunda década deste século) mostrassem coincidência, nota: "E para toda circunstância vale o seguinte: que só em conexão com a forma de distribuição da renda a racionalidade formal pode dizer-nos algo sobre o modo de abastecimento material ". ${ }^{15} \mathrm{E}$, mais adiante, traz à baila o problema básico: "As racionalidades material e formal (...) separam-se cabalmente entre si de forma tão ampla como inevitável. Esta irracionalidade fundamental $e$ insolúvel de economia é a fonte de toda 'problemática social'e especialmente de todo socialismo". ${ }^{16}$

Através das citações feitas tivemos em mira trazer maiores argumentos à tese que estamos defendendo de que a racionalidade empresarial não se esgota no âmbito da organização da empresa; que, uma vez que a racionalidade do empresário isolado enquanto "gerente" da empresa pode constituir ao mesmo tempo a irracionalidade do sistema, em seus outros papéis, como membro da classe em- presarial, tem de preocupar-se primordialmente em obviar tal irracionalidade, para que seu comportamento atinja a máxima racionalidade possível. Isto significa que, neste nível, a racionalidade do empresariado (classe) se manifestará, sobretudo, em sua atuação em relação às condições externas à empresa.

Em outras palavras, a racionalidade empresarial seria tanto mais adequada quanto mais combinasse os dois planos, o interno e o externo, de modo a garantir resultados proveitosos e duradouros, mesmo que dificilmente permanentes. ${ }^{17}$ Assim, de um lado, cada empresário teria de se voltar fundamentalmente para os problemas restritos de organização da sua empresa e de seu relacionamento, de caráter principalmente adaptativo, às condições vigentes. Neste nível se manifestaria o que chamamos de racionalidade interna. De outro lado, entretanto, como classe, a racionalidade dos empresários revelar-se-ia, realmente, em sua atuação no plano societário, de forma a manter, criar ou recriar condições que permitissem atingir, não só no presente, como no futuro, o fim precípuo da empresa capitalista. É o que chamamos de racionalidade externa. Em suma, a máxima racionalidade possível seria atingida quando o uso e coordenação dos meios transcendessem os estritos limites da empresa.

\section{CONCLUSÕES}

O emprego, freqüentemente impreciso, do termo "racional" por administradores, economistas e outros cientistas sociais e também por políticos decorre, sobretudo, do estabelecimento de uma sinonímia inexata entre conceitos que são diferentes por não abarcarem, dentro dos limites da extensão da definição, os mesmos atributos, ainda que possam conter alguns deles. Em nosso entender, preconceitos ideológicos podem contribuir largamente para esse uso ambíguo ou indevido do termo. Ainda que, na definição do conceito, a adequação dos meios utilizados aos fins propostos constitua seu caráter fundamental, colocando-se a ênfase nos meios, a relação não é suficiente para conter todo o conjunto de atributos compreendido pelo termo. Ain- 
da que o caráter de racional possa ser confirmado pela consecução dos resultados esperados, empregados os meios achados convenientes, o que se entende por racionalidade extravasa a relação mencionada.

Assim, uma ação social, para ser tão plenamente racional quanto possível, deve compreender a previsão, pelo sujeito da ação, das consequiências da mesma sobre a realidade em que atua. É relevante também, na definição do conceito:

a. a compreensão mútua, a mais perfeita possivel dentro das condições dadas, do significado recíproco das ações;

b. o máximo domínio possível das consequêencias futuras da ação; e, finalmente,

c. a criação de uma situação favorável à consecução dos objetivos do sujeito da ação.

Estas considerações gerais podem ser exemplificadas pela sua aplicação ao comportamento empresarial. A racionalidade deste comportamento está em manter um equilíbrio, ainda que precário, entre a organização interna da empresa e o sistema social global na qual está inserida, combinando os planos interno e externo. Ao atuar como membro isolado, o empresário tem que se preocupar em não criar "irracionalidades" ainda mais fortes no sistema (dadas como insolúveis, se bem que podendo ser mitigadas). Já que o empresariado, como classe, tem interesses diversos (não apenas econômicos, mas igualmente sociais, políticos etc.) a racionalidade de sua atuação se manifestará no equilíbrio conseguido entre os vários níveis, de modo que o atingimento dos objetivos num desses níveis não prejudique a consecução de outros, em nível diferente.

Ao distinguir, na atuação do empresariado, duas racionalidades complementares (interna e externa), desejamos salientar que a máxima racionalidade está condicionada pelo domínio maior ou menor da açāo reflexa dos próprios atos. Assim, uma ação poderia ser racional (entendido o termo, sempre, como uma relação de meios a fins) se considerada quanto aos seus efeitos imediatos (levar à consecução do fim), e irracional a lon- go prazo, por ter uma açāo reflexa desfavorável sobre a situação favorecedora da obtenção dos fins propostos, ou ainda, simplesmente, por não contribuir para facilitar sua consecução futura. Nestas condições, tal ação, a rigor, não poderia ser considerada racional.

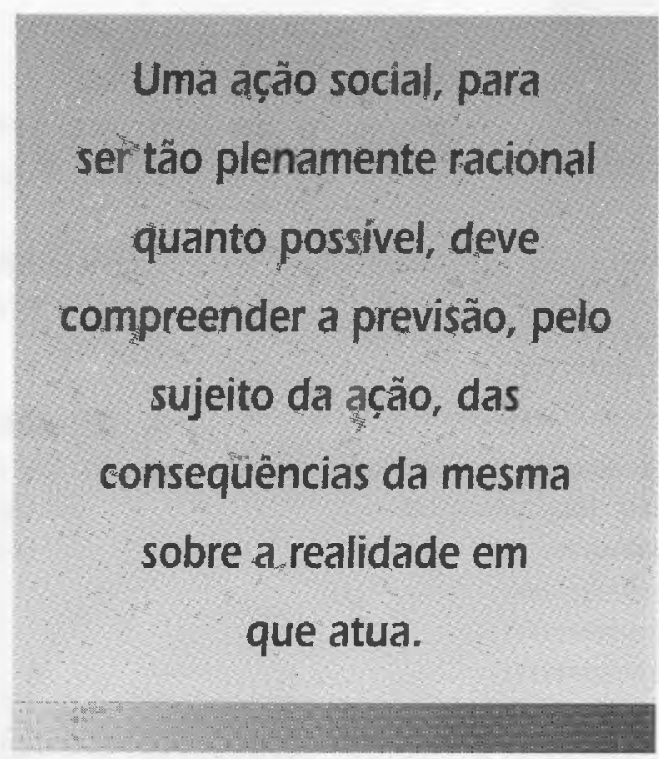

Assim mesmo o entende Max Weber, quando afirma que uma ação social é racional com relação a fins quando "determinada por expectativas no comportamento tanto de objetos do mundo exterior como de outros homens, e utilizando essas expectativas como condições ou meios para a obtenção de fins próprios racionalmente estabelecidos $e$ perseguidos" $18 \mathrm{Ou}$ ainda quando diz, talvez mais enfática e claramente, que "atua racionalmente com relação a fins quem oriente sua ação pelo fim, meios e conseqüências implicadas nela e para a qual estabeleça racionalmente os meios como os fins, os fins com as conseqüencias implicadas $e$ os diferentes fins possiveis entre $s i^{\prime \prime} .{ }^{19}$ Entretanto, o alcance da racionalidade mais ampla, que deverá englobar praticamente todos os papéis do empresário relacionados com o de agente não só econômico como político, será necessariamente limitado. De fato, como já se indicou, a consecuçăo desse grau máximo de racionalidade está condicionada pelas condições dadas, pelos imperativos do sistema no qual o agente atua. Será o próprio sistema, portanto, que determinará o âmbito da racionalidade interna e os limites da racionalidade externa.
14. Chama ele de "racionalidade formal de uma gestāo econômica ao grau de cálculo que the é tecnicamente possivel e que aplica realmente", denominado "racionalidade material ao grau em que o abastecimento de bens dentro de um grupo de homens (...) tenha lugar por meio de uma açāo social de caráter econômico orientada por determinados postulados de valor" (...) Salienta que enquanto o primeiro conceito é inequivoco, o segundo é completa. mente equivaco: "Significa só este conjunto de coisas: que a consideração não se satisfaz com o fato inequívoco (relativamente) e puramente formal de que se proceda e calcule de modo racional $\mathrm{em}$ relaçāo a fins com os meios factiveis tecnicamente mais adequados, mas que se coloquem exigências éticas, políticas, utilitárias, hedo nistas, estamentais, iqualitárias ou de qualquer outra classe e que desse modo se meçam as conseqüências da gestāo econômica ainda que seja plenamente racional do ponto de vista formal, isto $e_{s}$ calculável com respeito a valores ou a fins materiais". (Conforme WEBER Max. Economia y sociedad. Trad. de Jasé Medina Echavarría. México: Fondo de Cultura Económica, 1944, v. 1, p. 83.)

15. Idem, ibidem, p. 108.

16. Idem, ibidem, p. 110.

17. Considere-se que, aqui, para argumentar, estamos nos colocando na posiçāo do empreendedor capitalista e dentro dos quadros do sistema capitalista de produçāo.

18. Conforme WEBER, Max. Op. cit. v. 1, p. 22-3.

19. Idem, ibidem, p. 24. 